\title{
Pemanfaatan Data Global Precipitation Measurement (GPM) dan Standardized Precipitation Index (SPI) untuk Deteksi Kekeringan Meteorologis di Provinsi Papua Barat
}

\section{(Utilization of Global Precipitation Measurement (GPM) and Standardized Precipitation Index (SPI) for Meteorological Drought Detection in West Papua - Indonesia)}

\author{
Arif Faisol $^{\left.{ }^{*}\right)}$, Budiyono ${ }^{1)}$, Indarto ${ }^{2)}$, dan Elida Novita ${ }^{2)}$ \\ 1) Universitas Papua, Jln. Gunung Salju Amban - Manokwari - Papua Barat \\ 2) Universitas Jember, Jln. Kalimantan No.37 - Jember - Jawa Timur \\ $\left.{ }^{*}\right)$ email korespondensi: arif.unipa@gmail.com
}

\begin{abstract}
Drought is a natural disaster in Indonesia. The National Disaster Management Agency (BNPB) reports that West Papua Province has a moderate to high threat of drought. This study aims to analyze the level of drought in West Papua Province using Global Precipitation Measurement (GPM) data and the Standardized Precipitation Index (SPI) method. The results showed that throughout 2019 there was no meteorological drought in West Papua, only a few areas in Kaimana were rather dry in the January-March 2019 SPI. In general, the GPM data and the SPI method have quite good accuracy in describing the level of meteorological drought in The Province of West Papua is compared with the analysis of rainfall data and drought level maps released by the Meteorology, Climatology and Geophysics Agency (BMKG), so that the GPM data and SPI method can be used to monitor the level of drought in West Papua Province especially in agricultural areas.
\end{abstract}

Keywords: Global Precipitation Measurement (GPM), Standardized Precipitation Index (SPI), Drought.

\begin{abstract}
ABSTRAK
Kekeringan merupakan salah satu bencana alam di Indonesia. Badan Nasional Penanggulangan Bencana (BNPB) melaporkan bahwa Provinsi Papua Barat memiliki ancaman kekeringan yang sedang hingga tinggi. Penelitian ini bertujuan untuk menganalisis tingkat kekeringan di Provinsi Papua Barat menggunakan data Global Precipitation Measurement (GPM) dan metode Standardized Precipitation Index (SPI). Hasil penelitian menunjukkan bahwa sepanjang tahun 2019 di Papua Barat tidak terjadi kekeringan meteorologis, hanya beberapa wilayah di Kabupaten Kaimana yang agak kering pada SPI bulan Januari - Maret 2019. Secara umum data GPM dan metode SPI memiliki akurasi yang cukup baik dalam menggambarkan tingkat kekeringan meteorologis di Provinsi Papua Barat dibandingkan dengan analisis data hujan dan peta tingkat kekeringan yang dirilis oleh Badan Meteorologi, Klimatologi, dan Geofisika (BMKG), sehingga data GPM dan metode SPI dapat digunakan untuk memantau tingkat kekeringan di Provinsi Papua Barat khususnya pada kawasan pertanian.
\end{abstract}

Kata Kunci: Global Precipitation Measurement (GPM), Standardized Precipitation Index (SPI), Kekeringan. 


\section{PENDAHULUAN}

\section{Latar Belakang}

Kekeringan merupakan salah satu jenis bencana alam di Indonesia. Kekeringan merupakan suatu kondisi jumlah air yang tersedia dibawah kebutuhan air untuk kebutuhan hidup, pertanian, kegiatan ekonomi, dan lingkungan (BNPB, 2018). Badan Nasional Penanggulangan Bencana (BNPB) melaporkan bahwa beberapa wilayah di Papua Barat memiliki ancaman kekeringan yang tinggi, yaitu; Manokwari, Raja Ampat, Teluk Bintuni, Sorong Selatan, Teluk Wondama, Maybrat, dan ancaman kekeringan sedang yaitu; Sorong, Tambrauw, dan Fakfak (Kurniawan, Triutomo, Yunus, Amri, \& Hantyanto, 2014).

Secara spesifik terdapat 4 (empat) jenis kekeringan, yaitu; kekeringan meteorologi, kekeringan pertanian, kekeringan hidrologi, dan kekeringan sosial ekonomi (Wilhite \& Glantz, 1985). Kekeringan meteorologi disebabkan berkurangnya curah hujan dibandingkan kondisi rata-rata dalam periode waktu yang lama, kekeringan pertanian disebabkan kelembaban tanah dibawah level optimal, kekeringan hidrologi disebabkan menurunnya ketersediaan air dipermukaan dan bawah tanah, dan kekeringan sosial yang disebabkan berkurangnya ketersediaan air sehingga menganggu aktivitas manusia (Wilhite \& Glantz, 1985).

Terdapat 5 (lima) metode dan indikator yang dapat digunakan untuk memantau dan menilai tingkat kekeringan, yaitu metode meteorologi, kelembaban tanah, hidrologi, penginderaan jauh, dan pemodelan (World Meteorological Organization, 2016). Beberapa indeks yang telah dikembangkan untuk menganalisis tingkat kekeringan meteorologis, diantaranya palmer drought severity index (PDSI) (Palmer, 1965), effective drought index (EDI) (Byun \& Wilhite, 1999), standardized precipitation index (SPI) (Guttman, 1999), deciles index (DI), percent of normal index (PNI), rainfall anomaly index (RAI), China-Z index (CZI), modified China-Z index (MCZI), dan Z-score index (ZSI) (Salehnia, Bannayan, Co, Zarrin, \& Hoogenboom, 2017).

SPI merupakan metode yang digunakan secara luas untuk memantau tingkat kekeringan meteorologis dalam berbagai rentang waktu. Pada rentang waktu singkat, SPI terkait erat dengan kelembaban tanah sehingga banyak dimanfaatkan pada bidang pertanian, sedangkan pada rentang waktu lebih lama, SPI dapat dikaitkan dengan groundwater dan reservoir sehingga banyak dimanfaatkan pada bidang hidrologi. SPI telah digunakan untuk memantau kekeringan di Eropa (European Drought Observatory, 2019), Amerika (Weather National Service, 2020), dan Indonesia (BMKG, 2020a).

Peneliti didunia telah menguji performa SPI dalam mengestimasi tingkat kekeringan meteorologis, diantaranya penelitian yang dilakukan oleh Nosrati et al yang menggunakan metode SPI untuk mengestimasi tingkat kekeringan di provinsi Azarbaijan Barat - Iran. Hasil penelitian menunjukkan bahwa SPI memiliki akurasi yang kurang baik untuk rentang waktu yang pendek dan memiliki akurasi yang cukup baik untuk rentang waktu yang panjang (Nosrati \& Zareiee, 2011). Hasil studi yang dilakukan oleh Xia et al menunjukkan bahwa SPI pada rentang waktu 1 bulan, 3 bulan, dan 6 bulan lebih handal untuk memantau kekeringan di Cina dibandingkan rentang waktu 12 bulan (Xia et al., 2018). Karavitis et al melaporkan bahwa SPI dapat menggambarkan kondisi kekeringan di Yunani dengan sangat baik (Karavitis, Alexandris, Tsesmelis, \& Athanasopoulos, 2011), sedangkan hasil penelitian Kumar et al menunjukkan bahwa hasil analisis SPI cenderung under-estimate ketika curah hujan sangat rendah dan sangat tinggi (Kumar, Murthy, Sesha, \& Roy, 2009).

Informasi curah hujan merupakan input bagi SPI. Terbatasnya jumlah stasiun hujan dan stasiun klimatologi dengan penyebaran yang tidak merata di Provinsi Papua Barat mengakibatkan tingkat keterwakilan spasial data hujan sangat rendah. Global Precipitation Measurement (GPM) merupakan pengamat curah hujan berbasis satelit yang memiliki kemampuan melakukan perekaman data hujan diseluruh dunia setiap $2-4$ jam perhari serta memiliki resolusi spasial $10 \mathrm{~km}$ (Goddard Space Flight Center, 2013). Sejumlah penelitian didunia menunjukkan bahwa data hujan GPM memiliki akurasi yang cukup baik 
dibanding data hujan hasil pengamatan (Azka, Sugianto, Silitonga, \& Nugraheni, 2018; Verma \& Ghosh, 2018; Sun et al., 2018; Sungmin et al., 2017; Asong, Razavi, Wheater, \& Wong, 2017; Sungmin et al., 2017; Omranian, Sharif, \& Tvakoly, 2018; Ma et al., 2016; Chen, Qin, Shen, \& Zhang, 2016; Xu et al., 2017; Sharifi, Steinacker, \& Saghafian, 2016; Gaona, Overeem, Leijnse, \& Uijlenhoet, 2016). Hasil penelitian terdahulu juga menunjukkan bahwa data GPM memiliki penyimpangan sebesar $32 \%$ dibanding data hujan hasil pengukuran pada stasiun iklim di Papua Barat (Faisol, Budiyono, Indarto, \& Novita, 2019).

Beberapa peneliti telah menggunakan data GPM dan metode SPI untuk analisis kekeringan, diantaranya penelitian yang dilakukan oleh Zhu et al. yang menunjukkan bahwa data GPM dan SPI memiliki akurasi yang cukup baik dalam memantau tingkat kekeringan pada DAS Xiang - Cina (Zhu et al., 2019).

\section{Tujuan Penelitian}

Penelitian ini bertujuan untuk menganalisis tingkat kekeringan meteorologis di Provinsi Papua Barat menggunakan data GPM dan metode SPI.

\section{METODOLOGI PENELITIAN}

Alat

Peralatan yang digunakan dalam penelitian ini antara lain laptop dan perangkat lunak GIS (Quantum GIS).

\section{Bahan}

Bahan yang digunakan pada penelitian ini adalah data GPM perekaman 2014 - 2019 dan data hujan perekaman 1996 - 2019 dari automatic weather station (AWS) Manokwari, AWS Fakfak, AWS Sorong, dan AWS Kaimana, dan peta SPI tahun 2019 yang dirilis oleh Badan Meteorologi, Klimatologi, dan Geofisika (BMKG).

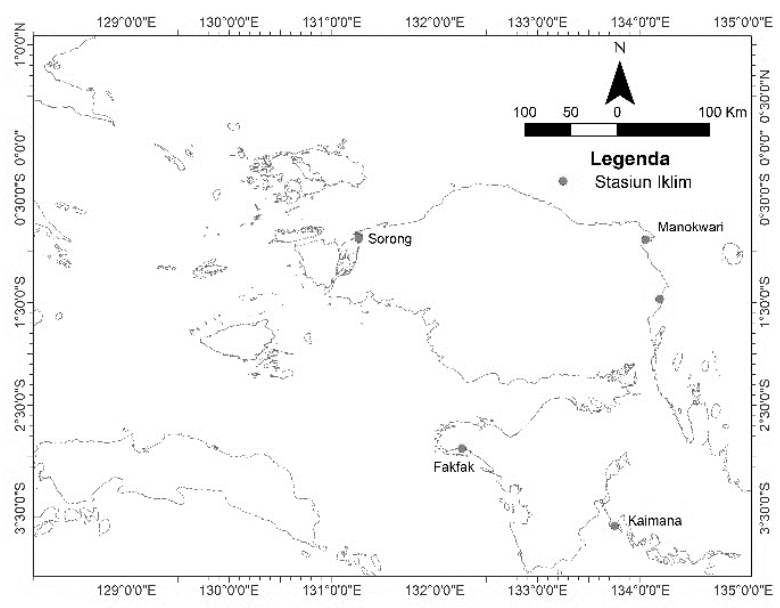

Gambar 1. Lokasi stasiun iklim

\section{Prosedur Penelitian}

Secara umum penelitian ini terdiri atas 3 (tiga) tahapan utama, yaitu:

a. Inventarisasi data

Tahapan ini bertujuan untuk menginvetarisasi data GPM, data AWS, dan peta SPI tahun 2019 yang dirilis oleh $\mathrm{BMKG}$.

b. Analisis data

Tahapan ini bertujuan untuk menganalisis tingkat kekeringan menggunakan data GPM dan metode SPI yang dihitung mengunakan persamaan berikut (Mishra \& Nagarajan, 2011)(Witono \& Cholianawati, 2011)(Widodo, 2013)(Topçu \& Seçkin, 2016)(Das, Choudhury, Gandhi, \& Joshi, 2016):

$$
S P I=\frac{X_{i}-\bar{X}}{\sigma}
$$

Keterangan:

SPI = standardized precipitation index

$\mathrm{Xi}=$ curah hujan bulan ke-i

$\bar{X} \quad=$ curah hujan bulanan rata-rata

Tabel 1. Klasifikasi kekeringan berdasarkan metode SPI dan peluang kejadian kekeringan (World Meteorological Organization, 2012)

\begin{tabular}{|c|c|c|}
\hline Indeks SPI & Kategori & $\begin{array}{l}\text { Peluang } \\
\text { kejadian }\end{array}$ \\
\hline$>2,00$ & sangat basah & $\begin{array}{c}\text { tidak } \\
\text { diterapkan }\end{array}$ \\
\hline $1,50-1,99$ & basah & $\begin{array}{c}\text { tidak } \\
\text { diterapkan }\end{array}$ \\
\hline $1,00-1,49$ & agak basah & $\begin{array}{c}\text { tidak } \\
\text { diterapkan }\end{array}$ \\
\hline$-0,99-0,99$ & normal & $\begin{array}{c}1 \text { kali dalam } 3 \\
\text { tahun }\end{array}$ \\
\hline$-1,49--1,00$ & agak kering & $\begin{array}{l}1 \text { kali dalam } \\
10 \text { tahun }\end{array}$ \\
\hline
\end{tabular}




\begin{tabular}{ccc}
\hline Indeks SPI & Kategori & $\begin{array}{l}\text { Peluang } \\
\text { kejadian }\end{array}$ \\
\hline$-1,99--1,50$ & kering & 1 kali dalam \\
& & 20 tahun \\
& 1 kali dalam \\
& 50 tahun \\
\hline
\end{tabular}

Analisis SPI dilakukan pada rentang waktu 3 bulan karena SPI 3 bulan merepresentasikan tingkat kekeringan pada pertanian (World Meteorological Organization, 2012). Disamping itu hasil studi yang dilakukan oleh Xia et al menunjukkan bahwa SPI 3 handal untuk memantau kekeringan (Xia et al., 2018).

c. Evaluasi data

Tahapan ini bertujuan untuk membandingkan antara hasil analisis SPI data GPM dengan hasil analisis data AWS dan peta SPI yang dirilis oleh BMKG.

\section{HASIL DAN PEMBAHASAN}

Secara umum data GPM dan metode SPI dapat menggambarkan distribusi spasial tingkat kekeringan di Provinsi Papua Barat dengan cukup baik. Berdasarkan hasil analisis data GPM perekaman 2014 - 2019 dan metode SPI, sepanjang tahun 2019 di Papua Barat tidak terjadi kekeringan meteorologis pada SPI 3 bulan, hanya beberapa wilayah di Kabupaten Kaimana yang agak kering pada SPI bulan Januari - Maret 2019. Distribusi spasial tingkat kekeringan di Papua Barat disajikan pada Gambar 2 sampai Gambar 4.

Jika dibandingkan dengan pengolahan data hujan, data GPM memiliki akurasi yang cukup baik dalam membangkitkan informasi tingkat kekeringan di Provinsi Papua. Beberapa faktor yang mempengaruhi akurasi data GPM dalam membangkitkan informasi tingkat kekeringan diantaranya rentang data yang digunakan. Pada penelitian ini data GPM yang digunakan memiliki rentang 6 tahun yaitu tahun 2014 - 2019, sedangkan data hujan yang digunakan memiliki rentang 24 tahun yaitu 1996 - 2019. Hal ini sesuai dengan hasil penelitian yang dilakukan oleh Nosrati dan Zareiee bahwa akurasi SPI dipengaruhi oleh rentang waktu data yang digunakan (Nosrati \& Zareiee, 2011). Hasil analisis SPI tahun 2019 di Provinsi Papua Barat berdasarkan data hujan perekaman 1996 - 2019 disajikan pada Tabel 2, Gambar 5 sampai Gambar 8.
Tabel 2. Tingkat kekeringan di Provinsi Papua Barat berdasarkan pengolahan data hujan.

\begin{tabular}{lllll}
\hline Bulan & Manokwari & Sorong & Kaimana & Fakfak \\
\hline Jan - & Normal & Normal & Normal & Normal \\
Mar & & & & \\
Apr - & Agak & Normal & Normal & Agak \\
Jun & Basah & & & kering \\
Juli - & Normal & Normal & Normal & Normal \\
Sep & & & & \\
\hline
\end{tabular}

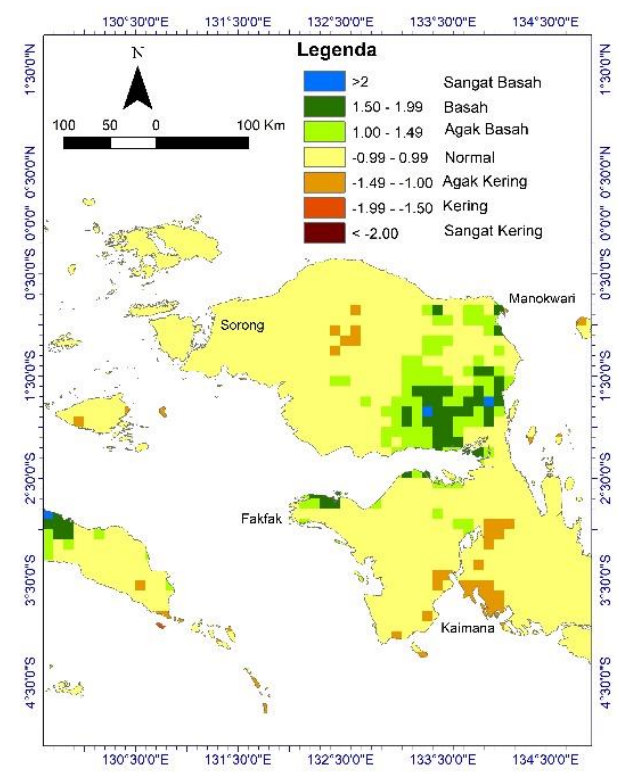

Gambar 2. SPI Januari - Maret 2019

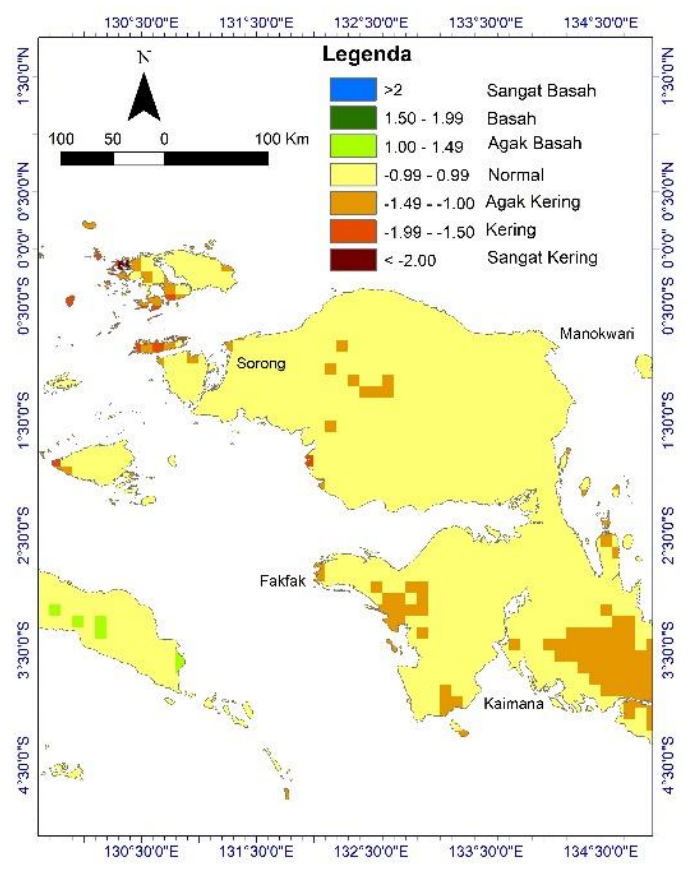

Gambar 3. SPI April - Juni 2019 




Gambar 4. SPI Juli - September 2019

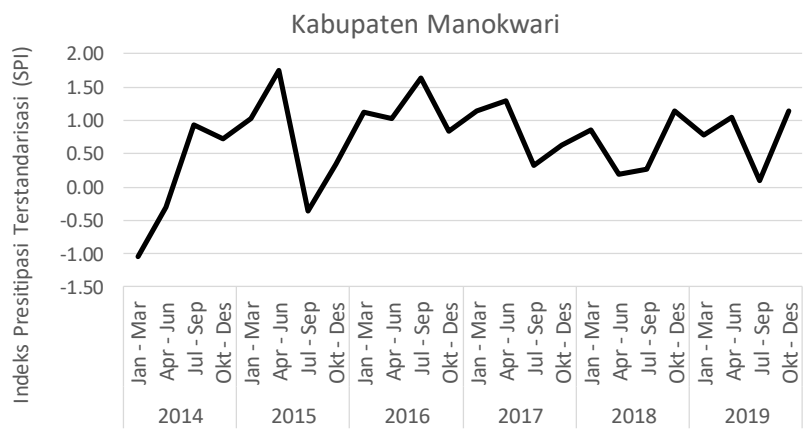

Gambar 5. SPI 3 bulan di Kabupaten Manokwari.



Gambar 6. SPI 3 bulan di Kabupaten Sorong Kabupaten Fakfak

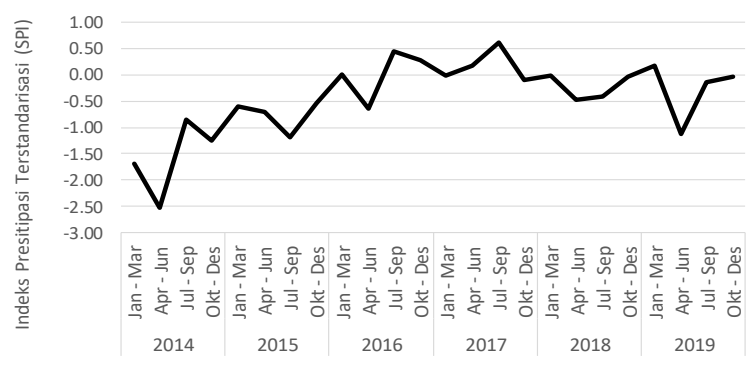

Gambar 7. SPI 3 bulan di Kabupaten Fakfak



Gambar 8. SPI 3 bulan di Kabupaten Kaimana (Hasil analisis, 2020)

Disamping itu, data GPM juga memiliki akurasi yang cukup baik dibandingkan dengan peta tingkat kekeringan yang dirilis oleh BMKG. Peta tingkat kekeringan di pulau Papua yang dirilis oleh BMKG berdasarkan metode SPI disajikan pada Gambar 9 sampai Gambar 11.
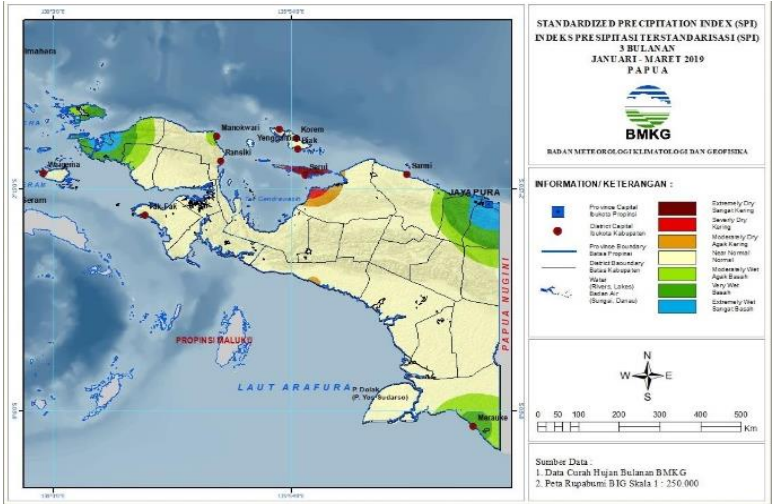

Gambar 9. SPI Januari - Maret 2019

(Sumber: BMKG, 2019b)

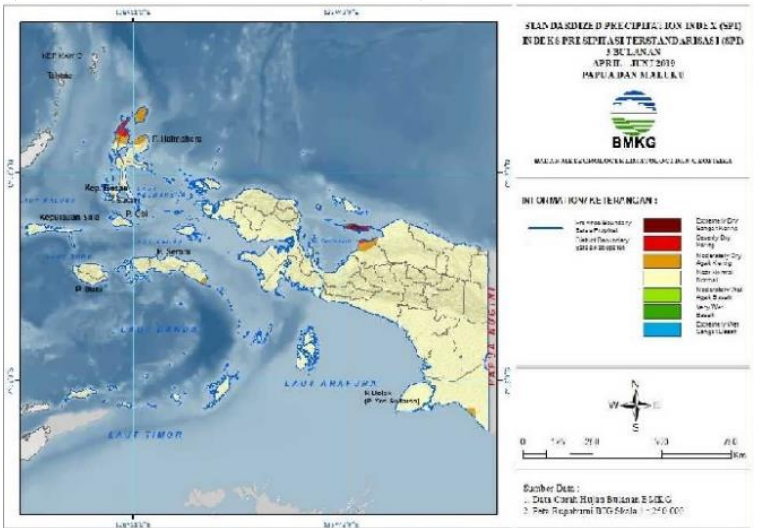

Gambar 10. SPI April - Juni 2019

(Sumber: BMKG, 2019a) 




Gambar 11. SPI Juli - September 2019 (Sumber: BMKG, 2019c)

\section{KESIMPULAN}

Data GPM dan metode SPI memiliki akurasi yang cukup baik dalam menggambarkan tingkat kekeringan meteorologis di Provinsi Papua Barat sehingga dapat digunakan untuk memantau tingkat kekeringan di Provinsi Papua Barat khususnya pada kawasan pertanian, karena sector pertanian sangat rentan terhadap kekeringan. Disamping itu akurasi hasil analisis dapat ditingkatkan melalui peningkatan rentang waktu data yang digunakan, sehingga perlu dilakukan kajian kekeringan menggunakan pengamat curah hujan berbasis satelit yang memiliki rentang waktu yang panjang, misalnya Climate Hazards Group Infrared Precipitation with Stations (CHIRPS) yang memiliki perekaman data hujan berbasis satelit sejak tahun 1981 sampai sekarang.

\section{UCAPAN TERIMA KASIH}

Penulis mengucapkan terima kasih kepada RISTEKDIKTI yang telah membiayai penelitian ini melalui skema Penelitian Kerjasama Antar Perguruan Tinggi no kontrak 198/SP2H/LT/DRPM/2019 dan Universitas Jember sebagai intitusi tim mitra.

\section{DAFTAR PUSTAKA}

Asong, Z. E., Razavi, S., Wheater, H. S., \& Wong, J. . (2017). Evaluation of Integrated Multisatellite Retrievals for GPM ( IMERG ) over Southern Canada against Ground Precipitation
Observations : A Preliminary Assessment. Journal of Hydrometeorology, 18, 1033-1050. https://doi.org/10.1175/JHM-D-160187.1

Azka, M. A., Sugianto, P. A., Silitonga, A. K., \& Nugraheni, I. R. (2018). Uji Akurasi Produk Estimasi Curah Hujan Satelit GPM IMERG di Surabaya, Indonesia. Jurnal Sains \& Teknologi Modifikasi Cuaca, 19(2), 83-88.

BMKG. (2019a). The Standardized Precipitation Index Juni 2019. Retrieved February 18, 2019, from https://www.bmkg.go.id/berita/?p=thestandardized-precipitation-index-june2019\&lang=ID\&tag=indeks-presipitasiterstandarisasi

BMKG. (2019b). The Standardized Precipitation Index Maret 2019. Retrieved February 17, 2020, from https://www.bmkg.go.id/berita/?p=thestandardized-precipitation-index-maret2019\&lang=ID\&tag=spi

BMKG. (2019c). The Standardized Precipitation Index September 2019. Retrieved February 18, 2020, from https://www.bmkg.go.id/berita/?p=thestandardized-precipitation-indexseptember-2019\&lang=ID\&s=detil

BMKG. (2020a). The Standardized Precipitation Index Desember 2019. Retrieved February 1, 2020, from https://www.bmkg.go.id/iklim/indekspresipitasi-terstandarisasi.bmkg

BMKG. (2020b). The Standardized Precipitation Index Desember 2019. Retrieved February 18, 2020, from https://www.bmkg.go.id/iklim/indekspresipitasi-terstandarisasi.bmkg?p=thestandardized-precipitation-indexdesember-2019\&tag=spi\&lang=ID

BNPB. (2018). Definisi dan Jenis Bencana. Retrieved November 9, 2018, from https://bnpb.go.id//definisi-bencana

Byun, H.-R., \& Wilhite, D. A. (1999). Objective Quantification of Drought Severity and Duration. American 
Meteorological Society, 12(September), 2747-2756.

Chen, Z., Qin, Y., Shen, Y., \& Zhang, S. (2016). Evaluation of Global Satellite Mapping of Precipitation Project Daily Precipitation Estimates over the Chinese Mainland. Advances in Meteorology, 2016, 15 https://doi.org/http://dx.doi.org/10.1155/ 2016/9365294

Das, S., Choudhury, M. R., Gandhi, S., \& Joshi, V. (2016). Application of Earth Observation Data and Standardized Precipitation Index Based Approach for Meteorological Drought Monitoring , Assessment and Prediction Over Kutch , Gujarat, India. International Journal of Environment and Geoinformatics, 3(2), 24-37.

European Drought Observatory. (2019). Standardized Precipitation Index ( SPI ).

Faisol, A., Budiyono, B., Indarto, I., \& Novita, E. (2019). Evaluasi Data Hujan Harian Global Precipitation Measurement (GPM) versi ke-6 di Provinsi Papua Barat. Seminar Nasional MIPA UNIPA IV Tahun 2019, 147-154. Retrieved from https://prosiding.fmipa.unipa.ac.id/index. php/SNMIPAUNIPA/article/download/4 $0 / 31$

Gaona, M. F. R., Overeem, A., Leijnse, H., \& Uijlenhoet, R. (2016). First-Year Evaluation of GPM Rainfall over the Netherlands: IMERG Day 1 Final Run ( V03D ). American Meteorological Society, 2016, 2799-2814. https://doi.org/10.1175/JHM-D-160087.1

Goddard Space Flight Center. (2013). Global Precipitation Measurement (GPM) Science Implementation Plan. Greenbelt: NASA.

Guttman, N. B. (1999). Accepting The Standardized Precipitation Index: a Calculation Algorithm. Journal of The American Water Resource Association, 35(2), 311-322.
Karavitis, C. A., Alexandris, S., Tsesmelis, D. E., \& Athanasopoulos, G. (2011). Application of the Standardized Precipitation Index (SPI) in Greece. Water, 3, 787-805. https://doi.org/10.3390/w3030787

Kumar, M. N., Murthy, C. S., Sesha, M. V. R., \& Roy, P. S. (2009). On the use of Standardized Precipitation Index ( SPI ) for drought intensity assessment. Meteorological Application, 16(April), 381-389. https://doi.org/10.1002/met

Kurniawan, L., Triutomo, S., Yunus, R., Amri, M. R., \& Hantyanto, A. A. (Eds.). (2014). Indonesian Disaster Risk Index (1st ed.). Bogor: Indonesian National Disaster Management Organisation (BNPB).

Ma, Y., Tang, G., Long, D., Yong, B., Zhong, L., Wan, W., \& Hong, Y. (2016). Similarity and Error Intercomparison of the GPM and Its Predecessor-TRMM Multisatellite Precipitation Analysis Using the Best Available Hourly Gauge Network over the Tibetan Plateau. Remote Sensing, 8(569), 1-17. https://doi.org/10.3390/rs8070569

Mishra, S. S., \& Nagarajan, R. (2011). SpatioTemporal Drought Assessment in Tel River Basin using Standardized Precipitation Index ( SPI ) and GIS. Geomatics, Natural Hazards and Risk, 2(1), 79-93. https://doi.org/10.1080/19475705.2010.5 33703

Nosrati, K., \& Zareiee, A. R. (2011). Assessment of meteorological drought using SPI in West Azarbaijan Province, Iran. Journal of Applied Sciences and Environmental Management, 15(4), 563569.

Omranian, E., Sharif, H. O., \& Tvakoly, A. A. (2018). How Well Can Global Precipitation Measurement ( GPM ) Capture Hurricanes? Case Study: Hurricane Harvey. Remote Sensing, 14. https://doi.org/10.3390/rs10071150

Palmer, W. C. (1965). Meteorological Drought. Washington DC. 
Salehnia, N., Bannayan, M., Co, T. L., Zarrin, A., \& Hoogenboom, G. (2017). Estimation of Meteorological Drought Indices based on AgMERRA Precipitation Data and Station-observed Precipitation Data. Journal of Arid Land, 9(October), 797-809. https://doi.org/10.1007/s40333-0170070-y

Sharifi, E., Steinacker, R., \& Saghafian, B. (2016). Assessment of GPM-IMERG and Other Precipitation Products against Gauge Data under Different Topographic and Climatic Conditions in Iran: Preliminary Results. Remote Sensing, 8(135), 24. https://doi.org/10.3390/rs8020135

Sun, W., Sun, Y., Li, X., Wang, T., Wang, Y., Qiu, Q., \& Deng, Z. (2018). Evaluation and Correction of GPM IMERG Precipitation Products over the Capital Circle in Northeast China at Multiple Spatiotemporal Scales. Advances in Meteorology, 2018, 14 pages.

Sungmin, O., Foelsche, U., Kirchengast, G., Fuchsberger, J., Tan, J., \& Petersen, W. A. (2017). Evaluation of GPM IMERG Early , Late , and Final rainfall estimates using WegenerNet gauge data in southeastern Austria. Hydrology and Earth System Science, 21, 6559-6572.

Topçu, E., \& Seçkin, N. (2016). Drought Analysis of the Seyhan Basin by Using Standardized Precipitation Index ( SPI ) and L-moments. Journal of Agricultural Sciences, 22, 196-215.

Verma, P., \& Ghosh, S. K. (2018). Study of GPM-IMERG Rainfall Data Product for Gangotri Glacier. The International Archives of the Photogrammetry, Remote Sensing and Spatial Information Sciences, XLII(November), 20-23. Dehradun.

Weather National Service. (2020). United States Drought Information. Retrieved February 1, 2020, from https://www.cpc.ncep.noaa.gov/products /Drought/
Widodo, N. (2013). Analisis dan Pemetaan Indeks Kekeringan Meteorologis Menggunakan Data Satelit TRMM dari 36 Titik Stasiun BMKG di Pulau Sumatera. Institut Pertanian Bogor.

Wilhite, D. A., \& Glantz, M. H. (1985). Understanding the Drought Phenomenom: The Role of Definition. Water International, 10, 111-120.

Witono, A., \& Cholianawati, N. (2011). Deteksi dan Prediksi Kekeringan Meteorologis di Sumatera Selatan Menggunakan Satelit TRMM. Seminar Nasional Sains Atmosfer Dan Antariksa 2011, (November), 8.

World Meteorological Organization. (2012). Standardized Precipitation Index User Guide (1st ed.). Geneva: World Meteorological Organization.

World Meteorological Organization. (2016). Handbook of Drought Indicators and Indices (2nd ed.). Geneva: World Meteorological Organization and Global Water Partnership.

Xia, L., Zhao, F., Mao, K., Yuan, Z., Zuo, Z., $\&$ Xu, T. (2018). SPI-Based Analyses of Drought Changes over the Past. Remote Sensing, 10(171), 1-15. https://doi.org/10.3390/rs10020171

Xu, R., Tian, F., Yang, L., Hu, H., Lu, H., \& Hou, A. (2017). Ground validation of GPM IMERG and TRMM 3B42V7 rainfall products over southern Tibetan Plateau based on a high-density rain gauge network. Journal of Geophysical Research, 910-924. https://doi.org/10.1002/2016JD025418

Zhu, Q., Luo, Y., Zhou, D., Xu, Y., Wang, G., \& Gao, H. (2019). Drought Monitoring Utility using Satellite-Based Precipitation Products over the Xiang River Basin in China. Remote Sensing, 11, 1-17. 